\title{
Socratic dialogue: a comparison between ancient and contemporary method
}

\author{
Laura Candiotto \\ Ca' Foscari University of Venice
}

These last years have witnessed the emergence and blossoming of practices inspired by philosophy on the didactic and pedagogical scene. In this context, Socrates's Philosophy represents one main point of reference. Socratic dialogue is now a model for a maieutic conception of teaching as well as for the constitution of dialogical communities and for an interrogative enquiry into reality. However, at times this recovery of the Socratic model is not exempt from misunderstandings and anachronisms. The aim of this article is to underline the main differences between the ancient and contemporary method.

\section{Socratic dialogue in the ancient world}

Socratic dialogue as a literary genre emerges in Athens during the 4th century BC, immediately after Socrates' death in 399 BC, in order to bear testimony and leave a durable trace of Socrates' life and method 1 These instances are at the basis of the development of the logoi sokratikoi genre, of which Plato is a proponent among many. The Socratic method, as a dialogic practice experienced by various interlocutors, has obviously an earlier origin, which can be traced back to the discursive or rhetoric practices characterizing democratic Athens. Public speeches, orations, discussions in court mark the emergence of an art of the word that is nurtured by democracy. Within this context, Socrates embodies an educational methodology and an idea of philosophical research markedly distinct from methodologies which were fashionable at the time, especially those of the sophists. Also the sophists practiced dialogue with their disciples, but the purpose and characteristics of

\footnotetext{
${ }^{1}$ Some researchers argue that the Socratic dialogue as literary genre was already present during Socrates' lifetime, assuming a didactic function. Cf. Rossetti (2011a).
}

M. Peters, P. Ghiraldelli, B. Žarnić, A. Gibbons (eds.) 
their method were different from the Socratic approach.

The first Platonic dialogues (the dialogues written by Plato immediately after the death of Socrates; those credited as authentic by most scholars are: Apology of Socrates, Menexenus, Protagoras, Laches, Republic Book I, Charmides, Euthyphro, Lysis, Hippias Major, Ion, Hippias Minor, Crito, Euthydemus, Cratylus, Gorgias, Meno) represent a vivid testimony of the Socratic method: it is thus possible to extract from them crucial information to delineate the general characteristics of this approach 2

\section{The maieutical character of the Socratic dialogue}

The first and fundamental feature of the method is that it is a maieutic method. Maieutics (literally, midwifery) can be defined as an art which, by operating through dialogue (the basic mode of dialogue is that of questions and answers), enables the soul to give birth to the truth it seeks. The truth is already present in the soul of the seeker: the Socratic questioning is the modality through which Socrates helps his interlocutor to discover the truth he already possesses. The dialogue enables, within a joint research, to get closer to the truth, it allows the interlocutor to find out the truth in first person, avoiding thus dogmatic expositions on the teacher's part. A knowledge which is not experienced in first person by the interlocutor cannot be acknowledged as true, as it is necessarily perceived by him/her as something external: accordingly, it does not possess the strength to compel the subject towards a conduct consistent with its specifications.

Maieutic knowledge unfolds thus as a form of practice implying the transformation of the subject involved in its elaboration. Through continuous questioning and answering, Maieutics enables the questioning soul to generate what s/he already knows and possibly, at a further stage, present discursively the knowledge it gave birth to. For the soul to be ready it is necessary a preliminary cleansing work addressing errors, false beliefs, stereotypes and prejudices; for achieving this purpose Socrates uses the Elenchos (refutation). The Elenchos articulates two moments: firstly, the thesis of the interlocutor is analyzed, secondly, objections are proposed. Examination and objections are strictly interconnected-given their mutual dependency, the Elenchos can be defined as a refuting process which tends to generate a positive thesis. The moment of analysis enables the individuation of contradictions intrinsic in the thesis, a process automatically resulting in its negation. The logical movement bringing to the negation of falsity is always accompanied, in the Socratic Method, by a psychological movement through which the interlocutor subjectivizes the contradictory character of his/her argument. If this moment of awareness (moment of negativity) is lacking, the Elenchos is ineffective and it cannot support the second phase of Socratic Maieutics, namely the production of a positive thesis 3

\footnotetext{
${ }^{2}$ For an analysis of the Socratic method in Plato's first dialogues, cf. L. Candiotto (2012a).

${ }^{3}$ The passage of the Plato's Sophist describing the Noble Sophistic is enlightening in this sense, cfr.
} 


\section{The practical relevance of the dialogue topic}

The second key feature of the Socratic Method is its ethical, political and educational relevance. The topics debated by Socrates and his interlocutors in the first Platonic dialogues establish always a strict connection between working on one's self and improving the life of the polis. Socrates urges the subject to take care of his soul in order to be good, beautiful and just 4 The pedagogic valence of the Socratic Method builds upon this basis: philosophical research is a pedagogical modality which Socrates shapes in order to enable his interlocutors to improve. From this perspective, it is possible to affirm, with Pierre Hadot $(1995,2002)$, that philosophical research, in its dialogic form, is Socrates' and Plato's main spiritual exercise. Furthermore, the debated themes are always interesting for the interlocutor: the examples adopted by Socrates are interesting for him/her as they always relate to his/her daily life. It is no coincidence then if in the Laches, where the interlocutors are two strategists, the argument is courage, or if in the Charmides, where the interlocutors are two figures that will play an important historical role in Athenian politics (Critias and Charmides) the primary emphasis is on temperance. Socrates and Plato, in fact, considered temperance as a necessary skill for a good politician. However, these considerations imply neither that Socratic dialogues are always successful, nor a constant openness on the part of Socrates' interlocutors - quite the contrary. For instance, in Gorgias it is possible to notice both ferocious defenses by the interlocutor and violent refutations by Socrates. In my opinion, this signals Socrates' and Plato's interest in criticizing the political situation of the time through a refutation of its representatives. By refuting Callices, Socrates demonstrates his inadequacy to the audience; Socrates is aware that Callices is not willing to be "purified" and thus directs his elenctic action towards the public attending the debate.

\section{The collaboration of interlocutors and their partaking in "a philosophical form of life"}

The third main feature concerns the type of relation which develops between Socrates and his interlocutors 5 On the one hand, Socrates emphasizes that the interlocutors must collaborate towards a common goal (unveiling truth), rather than asserting their preeminence through a kind of dialogical fight (this aspect marks a crucial difference from sophistry). Philosophical research enacted through dialogue is thus a joint research, unfolding in a collective context towards collective goals. This communitarian aspect is not accidental, but a central prerequisite and instrument of orientation without which the research could

\footnotetext{
Plat., Soph. 230 b4-d4.

${ }^{4}$ For a contemporary reading of this theme, cfr. M. Foucault (2001).

${ }^{5}$ Elsewhere, I called this particular process "retroactive elenchos". To approach this theme more in detail cf. Candiotto (2012b).
} 
not be successful, not even at a gnoseological level. Of course, it is possible to think alone, however in this case it is always necessary to test dialogically the correctness of what has been thought. In general terms, apart from this case Socrates emphasizes how the truth can be discovered maieutically only through dialogue, thus through a shared dimension of research - even if the moment in which the truth is grasped is individual and cannot be completely presented at a linguistic level. These various facets of the Socratic Method are clearly delineated in Plato's Seventh Letter (Plato, Seventh Letter, 340b-345c), where the author underlines that philosophical research through dialogue is fruitful only if the subjects involved in the dialogue partake in a common form of life, a philosophical form of life, and the achievement of knowledge is a sudden event taking place in the soul of the person involved in the dialogical activity. A fundamental nexus is thus established between community and self-knowledge-intending with self-knowledge an intellectual achievement which is not an end in itself but, again, oriented towards the communitarian aspect of the common good.

For Plato, philosophy operates within a social network where the example and teaching of a single person cannot suffice. The whole community must practice philosophy. Not only political action supported by philosophy, but philosophical knowledge itself requires a communitarian dimension. Also the aspect concerning theoria has to do with what is common rather than individual. Plato argues in fact that philosophical knowledge emerges in the individual soul thanks to the dialogue among people who share a given form of life and which are constantly in contact with each other.

There neither is nor ever will be a treatise of mine on the subject [philosophy]. For it does not admit of exposition like other branches of knowledge; but after much converse about the matter itself and a life lived together, suddenly a light, as it were, is kindled in one soul by a flame that leaps to it from another, and thereafter sustains itself.

(Plato, Seventh Letter, 341c4-d2)

The truth is grasped by each person by dialoguing with oneself and others. Truth is never possessed achieved by a single individual: it cannot be grasped independently from dialogical interaction except in rare cases, and even such cases require a proof of their veridicity which can only be obtained within a discursive setting.

However, differently from Dionysius, they were aware that those [insights acquired through dialogue] were not their own thoughts, but a "possession shared amongst friends" of the Academy, emerged through that admirable exchange of spiritual energies implying giving and receiving; in the mediation of acting and experimenting, which establishes the academia as the highest form and eternal model of any community of culture, education and life, the 
quintessence of any community of men bound by a reciprocal understanding.

(Stenzel 1966, p. 3026)

Only an adequate preparation or propaedeutic can lit the flame of philosophical knowledge. This propaedeutic is obtained on the one hand through a form of communitarian life, where interests and philosophical discussions are shared, on the other hand through a quotidian individual study and through the radical choice to live a specific form of lifenamely, a philosophical one. It is crucial to emphasize how, from this perspective, the highest forms of philosophical knowledge depend, on the one hand, on markedly material circumstances - to live in a specific place, with certain people and during a given span of time; on the other, on aspects which refer to a personal choice. Philosophical knowledge cannot be enclosed in a dogmatic definition as it emerges in a particular "shape", consubstantial with a relational-dialogic context. On the other hand, the relation ensuing between Socrates qua proponent of Maieutics and his interlocutors is asymmetrical. Socrates, although reiterating his lack of knowledge, guides his interlocutor towards pre-fixed avenues of enquiry, singles out viable paths through fictitious questions (Longo 2000) causes paradoxes and aporias to expose errors, orientates the research towards themes that bring into question the whole being of his interlocutor. Socrates is thus a guide that knows where to lead his interlocutor, even if he does not know exactly which type of knowledge such interlocutor will be able to attain. The asymmetry between Socrates maieutician and his interlocutors is different from the traditional asymmetry that exists in the relationship between teacher and disciple, where the teacher transmits a specific range of knowledge to the disciple. The asymmetry between Socrates and his interlocutors is underlined by Socrates' solid methodological knowledge and in his role as a guide throughout the research journey. In this sense, Socrates' approach differs both from the dogmatic knowledge typically transmitted by the traditional teacher and from the Sophists' conception of dialogue as deployment of dialectical weaponry functional to subdue the interlocutors.

\section{The use of rhetorical strategies in the dialogue}

In recent years, however, it has been pointed out (Kohan 2009; Rossetti 2011b) how Socrates does not really listen to his interlocutors. Not unlike the Sophists, Socrates makes use of a number of strategies to control the dialogue. Such strategies are the fourth fundamental characteristic of the Socratic dialogue. Livio Rossetti furthers this thread of analysis by emphasizing how the emotional style adopted by Socrates was intended to corner his interlocutor. It is interesting, however, to understand why Socrates deemed useful to push the interlocutor in difficult positions. Arguably, the strategy which effected emotions was functional for what Socrates aimed to elicit in the interlocutor (and in the public): not a substantive doctrine but the awareness of contradictions. The emotional

\footnotetext{
${ }^{6}$ My translation.
} 
preparation, creating a particular atmosphere, was functional to the interiorization of a specific dilemma or latent problem. This process could bring the subject to live a liberating emotion able of disclosing unexpected perspectives. Rossetti points out that the effectiveness of the Socratic dialogue does not rest on the strength of the proposed arguments (they are often incomplete or erroneous), but in rhetorical techniques which display, among other things, a sapient use of emotions. Moreover, Socrates used to ridicule interlocutors and often enacted violent patterns of refutation. When he was more lenient he applied, at most, a paternalistic style.

Rossetti's reading enables us to grasp the rhetorical strategies used by Socrates. These are specific dialogical modalities which aim to produce a given effect in the interlocutor. Some of them may appear similar to the ones employed by the Sophists, however, in my perspective, their different purpose marks a cleavage between the two: for Socrates the ultimate aim of dialogical interaction is the improvement of the interlocutor (or the public), through the recognition of one's errors and, possibly, the achievement of truth, whilst for the sophists the main goal is the agonistic defeat of the interlocutor as a way to obtain fame, honor and glory. In fact, the Socratic asking invites constantly the interlocutor to question him/herself within a perspective of "self-knowledge" and care of the self.

\section{The self-improvement of the interlocutors as the purpose of the dialogue}

The model of philosophy proposed by Socrates is thus consistent with the definition of philosophy as art of life (Horn 1998), as daily practice enabling to live a dignified life, virtuous and therefore happy. Through a philosophic interpretation of the Delphic maxim "know thyself", Plato, through Socrates, establishes philosophy, and in particular philosophical dialogue, as the most profound form of education available to individuals and society.

This last aspect introduces a fifth characteristic, concerning the purpose of Socratic dialogue, and more specifically its gnoseological-ethical-political purpose, aiming to improve both the individual and the polis that $\mathrm{s} / \mathrm{he}$ inhabits. It is necessary to emphasize here that the figure of Socrates qua model of philosopher is crucial for the development of the ancient Socratic dialogue in its platonic acception.

Socrates embodies the philosopher who does not know but is aware of his lack of knowledge. For this reason Socrates addresses those who think to possess knowledge; by declaring his ignorance, he forces them to question their knowledge and to recognize its lack of foundations. The beginning of any true research is in fact the awareness of one's own ignorance and the liberation from his/her own mistakes of judgment. Socrates defines his research method as follows, speaking in first person: 
Of what sort am I? One of those who would be glad to be refuted if I say anything untrue, and glad to refute anyone else who might speak untruly; but just as glad, mind you, to be refuted as to refute, since I regard the former as the greater benefit, in proportion as it is a greater benefit for oneself to be delivered from the greatest evil than to deliver someone else. For I consider that a man cannot suffer any evil so great as a false opinion on the subjects of our actual argument.

(Plato, Gorgias, 458a)

Socratic dialogue leads to aporia, however aporia is not to be intended as a negative outcome - it rather exemplifies a first great dialogical conquest: the awareness of error, of not knowing. One main outcome of Socratic dialogue is thus an urgent need to continue researching, starting in the first place from a process of self- examination. By investigating the opinions of his interlocutors, Socrates enables them to call into question themselves and their own mode of life.

Nicias: You strike me as not being aware that, whoever comes into close contact with Socrates and has any talk with him face to face, is bound to be drawn round and round by him in the course of the argument- though it may have started at first on a quite different theme - and cannot stop until he is led into giving an account of himself, of the manner in which [188a] he now spends his days, and of the kind of life he has lived hitherto.

(Plato, Laches, 187e-188a)

Socrates possesses a knowledge different from those paradigms which were conventional at the time, it is not a theory which can be taught but rather a sapience immediately conducive to practice: the necessity to research and embody an ethical form of common life. Socrates does not aim to limit the discussion to concepts such as "good", "fair", "pious", etc., but wishes that these concepts, once made available to the interlocutor by means of rational demonstration, become for him/her a form of life. Crucially, Socratic knowledge qua work on the self is an appeal to "being". Socrates knows the value of moral action as such action is implied by his own choice, on his personal commitment, on a personal urgency to improve, and this is possible only starting from the awareness of one's own errors.

Accordingly, Socratic knowledge is "knowing how to live". The "art of living" is a mode of life oriented towards the good and animated by a constant strife to improve, to avoid errors; this attitude prevents the occurrence of evil to the person who has embraced this mode of existence.

... no evil can come to a good man either in life or after death...

(Plato, Apology, 41d) 


\section{The contemporary method}

The use of dialogue or discussion as philosophical inquiry (philosophical inquiry carried out as a dialogue or discussion) is a philosophical practice that never disappeared and that in the last forty years, thanks to a growing interest towards philosophical practices also by non-philosophers or specialists and beyond strictly epistemological concerns, produced (has been object of) a thriving experimentation in various fields and contexts. Hence the emergence of various of initiatives to practice philosophical dialogue collectively: Philosophy for children, Philosophy for Community, Cafè Philo, etc.

Socratic dialogue can be included in this group of practices; during the 20th century it has been redesigned in several formulations and re-proposed by various schools with different purposes, not only philosophical. The method has been applied, especially in the Anglo-Saxon world, in psychotherapy (especially cognitivist paradigms), in legal settings, in context of conflict mediation, in health care settings, in companies to facilitate the achievement of common objectives, in schools, etc. Here I will provide a general outline of contemporary Socratic dialogue focusing in particular on its elaboration in the German context. Arguably, such elaboration is the variant that remains closer to the spirit of ancient Socratic dialogue, although differing from it in some respects.

The philosophical thread in question originated in Germany in the second decade of the XX century, thanks to the work of Leonard Nelson and his disciples Gustav Heckmann and Minna Specht. Methodologically, the starting point of Socratic dialogue is a question that interests the research group and that is supported by a number of concrete examples. Usually, a participant proposes a personal experience prompting a philosophical question, which is thereby proposed to the group as starting point for research. Questions are generally related to moral and ethical fields, but can also refer to a gnoseological or ontological dimension.

The basic question is formulated according to the Socratic ti esti, "what is $x$ "? But it can also assume different shapes. It is crucial, in order for a productive common research to take place, that the participants find the question interesting and somehow close to their personal experience (in this respect it is possible to detect a similarity between Socratic dialogue and the first rule of biographic-supportive communication (Madera and Tarca 2007), which refers to autobiography and to a type of first-person philosophy). The initial formulation of the question will therefore affect the whole course of the common enquiry.

Once the question is asked, participants examine examples drawn from concrete life experiences: the discussion focuses, firstly, on the situation proposed by the participant who formulated the question, secondly, on other examples illustrated by other subjects participating in the dialogue. Starting from examples, philosophical research can produce a knowledge which is embodied, rather than abstract or distant from the experiences of the 
research participants. This process enables-as Socrates knew-an immediate involvement of interlocutors and the possibility of realizing the acquired knowledge in concrete forms of life. From a gnoseological perspective, this process tends to privilege induction over deduction and to emphasize how knowledge-also in its theoretical, general and even universal acception - can be discovered starting from sensible experience.

The discussion follows the exposition and analysis of examples. During this moment, the correctness of argumentative logic is emphasized, contradictions and fallacies are underlined whilst the group strives to individuate shared axioms. Incidentally, it is necessary to point out here how main presuppositions of the method are both a kind of rationalism, a specific confidence in human beings' rational capacity of achieving a form of coherent knowledge (a form of knowledge, itself rational) and a specific conception, typical of the modern age, of understanding truth in its logical-mathematical formulation. Contemporary philosophy highlighted the crisis of such model in different occasions. Whilst the validity of such position is open to debate, it is arguably necessary to be aware that adopting the Socratic method implies assuming a certain epistemological paradigm, characterized by its own strength and limitations. Also in the ancient method there was a tendency towards rationalism, however, for Socrates, the main emphasis is on the moral purpose of dialogical enquiry; Socrates was ready to set aside formal correctness if this could facilitate a moral improvement in the interlocutor (Dorion 2004). Anglo-Saxon commentators interested in Socratic dialogue, operating from an analytical perspective, often underscore logical inconsistencies in Socrates' arguments. In my perspective, however, these inconsistencies signal how, for Socrates, logical correctness was a valid instrument, but not the ultimate goal of the dialogue. Accordingly, in specific occasions it could be considered of secondary importance. Moreover, the "errors" were used with strategic purpose, assuming thus a rhetorical role.

In terms of the subjective disposition of the participant, Socratic dialogue requires an attitude of sincerity towards oneself and others, as well as trust in one's own capacity of enquiry and in that of other participants. Socrates himself emphasized this aspect, pointing out how the attitude of the interlocutor towards the enquiry and his guide was crucial to determine whether or not he could attain philosophical knowledge (Plato's Gorgias is exemplificative in this sense). In the dialogues written by Plato we often find interlocutors who cannot achieve a productive attitude as they are perched on their positions, unwilling to admit their mistakes. They do not trust Socrates, believing that he aims to obtain a heuristic-agonistic victory rather than to help them. Plato describes these charactersmostly sophists, rhetoricians, orators, politicians - in order to criticize Athenian society, demonstrating their low moral qualities and the way in which they pursue a life of fame, honor and glory.

Moreover, Plato staged hostile interlocutors for emphasizing Socrates' figure. Socrates was the teacher whose main activity was to liberate his interlocutors from error through strategies which were at times violent and that affected their emotions, and who subse- 
quently guided them in the search for truth. Accordingly, in the ancient Socratic dialogue finding hostile interlocutors was almost the norm.

The contemporary Socratic dialogue is, however, a freely chosen philosophical practice characterized by a form of symmetry among all the participants. Therefore, the above mentioned dynamics do not take place, except in the form of accidents due to participants' inability to maintain the required behavior. A positive disposition of the participants is thus a necessary prerequisite to implement the philosophical practice in question.

There is no figure like Socrates in the present Socratic dialogue. Within research groups, there is a moderator which acts more as a facilitator, rather than as a teacher or guide. His/her task is neither to orient discussion nor to intervene in relation to contents, but to verify that, during each step of the research, participants proceed with order towards shared forms of knowledge - forms which are obtained through a progressive agreement concerning the various points under discussion. We could say that each participant has the task of playing Socrates' role both for him/herself and for others.

It is thus possible to notice that the underlying assumptions of ancient and contemporary Socratic dialogues are noticeably different. In the first one, the truth to be known is already ontologically posited and the subjects participating in the dialogue follow a common path, punctuated by questions and answers, which leads them, thanks to an expert guide (Socrates), to approach truth maieutically. In the second case, truth is not predetermined but constructed within the dialogical-linguistic context through an agreement between research participants. In the first case, Socrates does not necessarily listened to his interlocutors, in the second availability to listen, empathy and sharing are essential conditions. The journey undertook by the subjects participating in contemporary Socratic dialogues is constructive, rather than revelatory. Ancient Socratic dialogue strove to achieve Truth whilst contemporary Socratic dialogue is in search of shared truths.

This fundamental difference- - based on the role of the facilitator, the relation between facilitator and interlocutors and the type of knowledge underpinning the entire processdepends on profound differences between the epochs and cultures in which these dialogic practices were implemented and between the overall conceptual frameworks of orientation animating their proponents.

Within fourth century Athens, Plato aimed to distance himself from the risks characterizing the emerging democracy - a political form which, in conjunction with the Sophists' teachings, resulted for him in relativism and instability in the ontological, gnoseological, moral and political fields. Against this risk, Plato constructed Socratic dialogues having as main point of reference a stable and universal ontology, which could support stable ethical and political instances. The 1920's in Germany, conversely, are characterized by the emergence of National Socialism, and Socratic dialogue was intended by Nelson as a practice of freedom, resistance and democratic struggle against dictatorial and totalitarian tendencies. 
The cultural and political backgrounds are thus extremely different and in some ways opposite. This is, in my opinion, the main reason behind the methodological difference separating ancient and contemporary forms of Socratic dialogue. In both cases, however, the dialogical practice was experienced as an activity which enabled a space of opposition vis-à-vis the dominant ideology of the times, thus the emergence of critical and autonomous thinking in the people participating in the dialogue.

The Socratic dialogue of German mold, not unlike the ancient Socratic dialogue handed down by Plato, is characterized by a marked political and pedagogical valence, an aspect that in other contemporary formulations of Socratic dialogue is not equally central.

Accordingly, in spite of the above mentioned substantial differences between the ancient method and the contemporary German approach, the latter can be considered as the worthiest heir of the spirit and attitude animating the former. Arguably, present forms adopting the Socratic method instrumentally, without a political and pedagogical background and using the method as a self-referential communicative strategy rather than as a pathway to improvement where the logical dimension is subordinated to the moral dimension involving the participants, risk in some cases to be closer to the method of the Sophists than to that of Socrates.

\section{References}

1. Candiotto, L. (2012a) Le vie della confutazione. I dialoghi socratici di Platone. Milano/Udine: Mimesis.

2. Candiotto, L. (2012b) Perché Platone scrisse dialoghi socratici? Analisi del ruolo dell'interlocutorio. In Una mirada actual a la filosofía grieca. Ponencias del II Congreso International de Filosofía Griega de la Sociedad Ibérica de Filosofía Griega, A. Bordoy (ed.), pp. 455-468. Palma de Mallorca/Madrid: Editiones de la SIFG.

3. Dorion, L. (2004) Socrate. Paris: Puf.

4. Foucault, M. (2001) L'herméneutique du sujet. Cours au Collège de France 19811982. Paris: Seuil/Gallimard.

5. Hadot, P. (1995) Qu'est-ce que la philosophie antique?. Paris: Éditions Gallimard.

6. Hadot, P. (2002) Exercises spirituels et philosophie antique. Paris: Éditions Albin Michel.

7. Horn, C. (1998) Antike Lebenskunst: Glück und Moral von Sokrates bis zu den Neupaltonikern. München: Verlag C. H. Beck oHG. 
8. Kohan, W. (2009) Socrates: el enigma de ensenar. Buenos Aires: Biblos.

9. Longo, A. (2000) La tecnica della domanda e le interrogazioni fittizie in Platone. Pisa: Scuola Normale Superiore.

10. Madera, R. and L.V. Tarca (2007) Philosophy as Life Path. Milano: Ipoc Press.

11. Rossetti, L. (2011a) Le dialogue socratique. Paris: Encre Marine/Editiones les Belles Lettres.

12. Rossetti, L. (2011b) Un Socrate che non ascolta: per esempio nell'Eutifrone. Peitho. Examina Antiqua 1(2): 25-38.

13. Stenzel, J. ([1928] 1966) Platone educatore. Bari: Laterza.

Encyclopaedia of Educational Philosophy and Theory

Received: May 102013

Accepted: August 102013 